\title{
Geographic variation in the costs of medical care for people living with HIV in British Columbia, Canada
}

\author{
Benjamin Enns ${ }^{1}$, Jeong Eun Min¹, Dimitra Panagiotoglou², Julio S. G. Montaner ${ }^{1,3}$, Bohdan Nosyk ${ }^{1,4^{*}}$ and On behalf \\ of the STOP HIV/AIDS study group
}

\begin{abstract}
Background: Regional variation in medical care costs can indicate heterogeneity in clinical practice, inequities in access, or inefficiencies in service delivery. We aimed to estimate regional variation in medical costs for people living with HIV (PLHIV), adjusting for demographics and case-mix.

Methods: We conducted a retrospective cohort study using linked health administrative databases of PLHIV, from 2010 to 2014, in British Columbia (BC), Canada. Quarterly health care costs (2018 CAD) were derived from inpatient, outpatient, prescription drugs, antiretroviral therapy (ART), and HIV diagnostics. We used a two-part model with a logit link for the probability of incurring costs, and a log link and gamma distribution for observations with positive costs. We also estimated quarterly utilization rates for hospitalization-, physician billing- and prescription drug-days. Primary variables were indicators of individuals' Health Service Delivery Area (HSDA). We adjusted cost and utilization estimates for demographic characteristics, HIV-disease progression, and comorbidities.
\end{abstract}

Results: Our cohort included 9577 PLHIV (median age 45.5 years, 80\% male). Adjusted total quarterly costs for all 16 HSDAs were within 20\% of the provincial mean, 8/16 for hospitalization costs, 16/16 for physician billing costs and 10/16 for prescription drug costs. Northern Interior and Northeast HSDAs had 38 and $44 \%$ lower quarterly non-ART prescription drug costs, and 2 and 5\% higher quarterly inpatient costs, respectively.

Conclusions: We observed limited variation in medical care costs and utilization among PLHIV in BC. However, lower levels of outpatient care and higher levels of inpatient care indicate possible barriers to accessing care among PLHIV in the most rural regions of the province.

Keywords: Medical costs, HIV, HIV costs, Regional costs, Medical utilization

\section{Background}

Regional variation in health care costs after adjustment for demographic and clinical factors can be indicative of inequities or a lack of well-defined clinical practice $[1,2]$. This topic has been the subject of considerable research in the United States and elsewhere [1,3-5], primarily to facilitate performance-based reimbursement or identify potentially inefficient health care providers [1]. While many of the drivers of regional disparities (which include

\footnotetext{
* Correspondence: bnosyk@cfenet.ubc.ca

'BC Centre for Excellence in HIV/AIDS, St. Paul's Hospital, 613-1081 Burrard St, Vancouver, BC V6Z 1Y6, Canada

${ }^{4}$ Faculty of Health Sciences, Simon Fraser University, Blusson Hall, Room

11300, 8888 University Drive, Burnaby, BC V5A 156, Canada

Full list of author information is available at the end of the article
}

variation in insurance coverage, multiple care providers, and other potential barriers to access $[6,7])$ may not be applicable in single-payer systems [8], regional variation was nonetheless identified among individuals with gastric cancer in Ontario [2], as well as among stroke patients in Alberta, though this was found to be diminishing over time [9]. In British Columbia, variation in healthcare costs was found to be modest in the general population after adjusting for individuals' characteristics [8].

Like other settings with concentrated HIV epidemics, there is substantial regional heterogeneity in the HIV epidemic within British Columbia (BC), demonstrated by differences in rates of new diagnoses, mortality rates, and availability of HIV-testing and harm reduction

(c) The Author(s). 2019 Open Access This article is distributed under the terms of the Creative Commons Attribution 4.0 International License (http://creativecommons.org/licenses/by/4.0/), which permits unrestricted use, distribution, and 
services [10, 11]. Health Authorities (HA) and Health Service Delivery Areas (HSDA) within the province are regional administrative boundaries by which health care funding is allocated and decisions are made (Additional file 1: Figure S1). HSDAs are heterogeneous in population density, with areas ranging from less than 0.5 , to more than 800 persons per square kilometer [12]. Furthermore, $88 \%$ of all combination antiretroviral therapy (ART)-prescribing physicians in $\mathrm{BC}$ practice in urban areas with specialists and more experienced ARTprescribing physicians easier to access [13]. Regional disparities in HIV care among BC's health regions have been consistently documented [10, 14, 15]. Most notably, ART engagement and viral suppression rates in 2016 were 7 and 23 percentage points lower, respectively, in the Northern HA compared to Vancouver Coastal HA which is home to over $50 \%$ of people living with HIV (PLHIV) in BC and $25 \%$ of the provincial population $[16,17]$.

Targeting geographic regions for structural improvements is more straightforward for health policy makers, given the organization of health care delivery, and potential barriers to access driven by geographic factors [12, 18, 19]. The BC Ministry of Health established HA-specific targets for the reach of HIV testing and access to ART, among other endpoints [11]. Disbursement of funds to meet these goals, as well as other supports, such as distribution of harm reduction supplies, is allotted by HA [11]. The province also has a number of programs targeting regional inequities in care, including rural retention programs which provide incentives for physicians to work in rural and remote communities, as well as expansion of telehealth services, which provide consultations to individuals in remote areas [12, 18]. Despite these concerted efforts to address regional variation in clinical practice and access to HIV care, it is unclear whether disparities in healthcare delivery persist. Analyzing the costs of the key forms of medical care for PLHIV across the province may help guide targeted intervention and thus support a localized response to the HIV/AIDS epidemic in BC.

Our aim was to quantify regional variation in medical care costs for PLHIV. We generated disaggregated estimates of costs and utilization rates for hospitalizations, physician billings and drug dispensations (both with and without the costs of ART medications) to identify potential associations between components, particularly in regions where lower levels of outpatient care could be leading to higher levels of inpatient utilization.

\section{Methods}

\section{Study design and data sources}

We conducted a retrospective cohort study using linked, provincial health administrative databases and disease registries, including the $\mathrm{BC}$ Centre for Excellence in HIV/AIDS drug treatment program and virology registries (antiretroviral dispensations, plasma viral load $(\mathrm{pVL})$ and $\mathrm{CD} 4$ tests) [20], the $\mathrm{BC}$ Centre for Disease Control HIV testing database (HIV diagnosis/risk group classification) [21], the Medical Services Plan (MSP) database (physician billing records) [22], the Discharge Abstract database (hospitalizations) [23], the BC PharmaNet database (non-antiretroviral drug dispensations) [24], and the BC Vital statistics database (deaths) [25]. Our data set comprised all HIV positive individuals identified within these databases, observed for at least two quarters between January 1, 2010 and March 31, 2014. Details regarding databases and cohort construction have been published elsewhere [17]. Our data included quarterly observations from HIV diagnosis to death, administrative loss to follow-up (no record of health service use for at least 18 months), or censorship as of March 31, 2014. We chose quarterly observations according to CD4 and pVL monitoring guidelines from the International Antiviral Society-USA (IAS-USA) [26]. The health care setting featured government-funded, single-payer care, covering inpatient and outpatient care, selected prescription drugs, laboratory monitoring, and antiretroviral medications.

\section{Study measures and variable creation}

Our primary outcome variable was the quarterly cost of medical care; calculated as the sum of inpatient, outpatient (physician fee-for-service billing claims), prescription drug costs (ART and non-ART), and diagnostic testing costs for each individual in our cohort. We estimated medical costs for PLHIV including the costs of ART medication, excluding ART medication, as well as costs of ART medication only for those receiving ART. We presented each of these analyses separately, as differential rates of ART uptake across HSDAs, combined with the high relative costs of antiretroviral medication, could potentially obscure differences in health care costs that indicated divergence from clinical practice standards or higher intensity of service provision among PLHIV. The methods for deriving these costs have been described previously [27, 28]. We adjusted all costs to 2018 Canadian Dollars (CAD), using the Canadian Consumer Price Index.

To support our primary analysis, and to provide further context as to which health care components showed greater regional differences among PLHIV, we estimated costs and utilization rates for hospitalizations, physician billing records and non-ART prescription drugs, respectively. We defined utilization outcomes as hospitalization days (days with an inpatient record), physician billing days (number of days in which an individual had at least one physician billing contact) - chosen to reflect the 
frequency of contacts rather than the number of individual MSP billing line items - and drug days prescribed (the total of all prescription days in a given quarter).

\section{Geographical health regions}

Our primary independent variables were a set of quarterly indicator variables for an individual's primary HSDA. We assigned one representative HSDA to each person in each quarter, depending on where an individual accessed health care services. We assigned time-varying indicators of HSDA due to high rates of intra-provincial migration for treatment among PLHIV [29, 30]. When an individual accessed health services in more than one HSDA in a quarter, we selected the HSDA in which an individual recorded the highest frequency of health care contacts as the representative HSDA.

We adjusted for a range of clinical factors, including measures of HIV disease progression (CD4 $<200$ cells/ $\mu \mathrm{L} ; 200-499$ cells $/ \mu \mathrm{L} ; \geq 500$ cells $/ \mu \mathrm{L}$; unmeasured) and ART status (ART-naïve, on-ART, and off-ART post-initiation (ART-dropout)). Additionally, we included the area under the $\log _{10}$ plasma viral load curve (AUC pVL) for 12 -months prior to the start of the quarter $(<2.7$; $2.7-2.99 ; 3-3.49$; $\geq 3.5$; unmeasured) to capture individuals' cumulative viral load over the previous 12-months. CD4 counts were taken from the most recent test prior to the start of the quarter, with previous test results carried forward for any missing observations, otherwise CD4 count was classified as unmeasured. AUC pVL measurements were also carried forward until the next non-missing observation, or the end of follow-up, otherwise AUC pVL was classified as unmeasured.

Demographic control variables included: age, sex, calendar year, transmission risk group, including: men who have sex with men (MSM); people who inject drugs (PWID); MSM who inject drugs (MWID); heterosexual/ other (HET), year of diagnosis, grouped as: pre-1996; 1997-99; 2000-03; 2004-07; 2008-14, and two separate measures of medical comorbidity, the drug prescriptionbased Chronic Disease Score (CDS) [31], and the Charlson Comorbidity Index (CCI) [32], based on hospital records, calculated as a moving average for the year prior to quarter start date. Finally, to account for individuals potentially re-locating for specialized, high-cost health care services, we included a variable indicating if an individual had moved in the previous 12 months, based on changes to annually updated MSP-registered billing addresses.

\section{Analysis}

To estimate quarterly health care costs, we fit a two-part generalized linear model (GLM) with logit link and binomial distribution for the probability of an individual incurring any costs, and a log link with gamma distribution for observations with non-zero costs [33]. We estimated costs per person-quarter by HSDA, holding all other covariates fixed at their overall sample means.

We estimated utilization rates for each component, using a two-part generalized linear model (GLM) with logit link and binomial distribution for the probability of an individual having any utilization, and a log link and negative binomial distribution for observations with non-zero utilization.

\section{Sensitivity analysis}

We repeated our primary analysis using representative HSDAs assigned by highest cost, rather than highest frequency of visits, in a given quarter. We conducted additional sensitivity analysis removing costs for services received through the Provincial Health Services Authority (which provides specialized health services to the entire province), which were otherwise assigned to an individual's representative HSDA, to determine if estimates for some HSDAs were disproportionately affected.

We created our analytical sample in SAS 9.4, and conducted statistical analysis in Stata 14.1.

\section{Results}

Our sample included 9577 individuals, with 140,137 person-quarters of observation between January 1, 2010 and March 31, 2014. Our cohort was 20\% female, with a median age of 45.5 years at baseline, $22.9 \%$ were known to be PWID and 28.5\% MSM (Table 1). Of the 16 total HSDAs, the largest served 7068 different individuals (73.8\% of all individuals in our sample), the smallest served 75 individuals, and $66.7 \%$ of individuals received services in more than one primary HSDA over the study period. Across HSDAs, the proportion of female personquarters ranged from 14.2-42.0\%, MSM person-quarters ranged from $3.8-44.9 \%$ and PWID person-quarters ranged from 18.1-59.0\%. Individuals were on ART in $74.6 \%$ of all person-quarters in our sample, Vancouver had the highest percentage (81.8\%), and the Northeast had the lowest (49.4\%) (Table 2).

Quarterly medical costs, adjusting for clinical and demographic factors and including ART, ranged from \$3775 [\$3407, \$4143] in Thompson Cariboo, to \$4912 [\$2636, \$7188] in East Kootenay, with all 16 HSDAs falling within $20 \%$ of the overall provincial mean (Fig.1a \& Additional file 1: Table S1). Adjusted quarterly costs, excluding ART, ranged from \$1232 [\$1052, \$1412] in Thompson Cariboo to $\$ 2043$ [ $\$ 785, \$ 3301]$ in East Kootenay, with 13/16 HSDAs falling within $20 \%$ of the overall provincial mean, and all 16 within $40 \%$ (Fig.1b \& Additional file 1: Table S1). Adjusted costs of ART medication per person-quarter on ART, ranged from \$4501 [\$4131, \$4871] for PLHIV in East Kootenay to 
Table 1 Summary statistics on individuals at baseline and summary statistics for medical costs by component

\begin{tabular}{|c|c|c|c|c|c|}
\hline \multirow{2}{*}{\multicolumn{2}{|c|}{ Rocling complos }} & \multicolumn{2}{|l|}{ Individuals (n) } & \multicolumn{2}{|l|}{$(\%)$} \\
\hline & & \multicolumn{4}{|c|}{ Baseline sample characteristics ( $n=9577$ ) } \\
\hline \multicolumn{2}{|l|}{ Female } & \multicolumn{2}{|l|}{1917} & \multicolumn{2}{|l|}{$20 \%$} \\
\hline \multicolumn{6}{|l|}{ Period of diagnosis: } \\
\hline \multicolumn{2}{|l|}{$<1996$} & \multicolumn{2}{|l|}{1297} & \multicolumn{2}{|l|}{$13.5 \%$} \\
\hline \multicolumn{2}{|l|}{ 1997-1999 } & \multicolumn{2}{|l|}{2186} & \multicolumn{2}{|l|}{$22.8 \%$} \\
\hline \multicolumn{2}{|l|}{$2000-2003$} & \multicolumn{2}{|l|}{1657} & \multicolumn{2}{|l|}{$17.3 \%$} \\
\hline \multicolumn{2}{|l|}{$2004-2007$} & \multicolumn{2}{|l|}{1789} & \multicolumn{2}{|l|}{$18.7 \%$} \\
\hline \multicolumn{2}{|l|}{$2008-2014$} & \multicolumn{2}{|l|}{2648} & \multicolumn{2}{|l|}{$27.6 \%$} \\
\hline \multicolumn{6}{|l|}{ HIV risk group: } \\
\hline \multicolumn{2}{|l|}{ PWID } & \multicolumn{2}{|l|}{2363} & \multicolumn{2}{|l|}{$24.7 \%$} \\
\hline \multicolumn{2}{|l|}{ MSM } & \multicolumn{2}{|l|}{3116} & \multicolumn{2}{|l|}{$32.5 \%$} \\
\hline \multicolumn{2}{|l|}{ MWID } & \multicolumn{2}{|l|}{753} & \multicolumn{2}{|l|}{$7.9 \%$} \\
\hline \multicolumn{2}{|l|}{$H E T^{\mathrm{a}}$} & 3345 & & $34.9 \%$ & \\
\hline Age (median) & & 45.5 & & - & \\
\hline & & & Cost Component & & \\
\hline & Hospitalization & Physician Billings & Non-ART Prescriptions & ART Prescriptions & Total Costs \\
\hline Zero-cost observations (\%) & $94.6 \%$ & $13.4 \%$ & $34.8 \%$ & $27.6 \%$ & $5.0 \%$ \\
\hline Positive-cost observations & & & & & \\
\hline Mean & $\$ 14,273$ & $\$ 530$ & $\$ 711$ & $\$ 4741$ & $\$ 5712$ \\
\hline SD & $(\$ 19,635)$ & $(\$ 946)$ & $(\$ 1376)$ & $(\$ 1260)$ & (\$7005) \\
\hline Skewness & 4.2 & 7.7 & 9.4 & 1.9 & 10.7 \\
\hline Kurtosis & 28.8 & 99.1 & 202.6 & 7 & 213.5 \\
\hline 50th percentile & $\$ 7629$ & $\$ 287$ & $\$ 239$ & $\$ 4689$ & $\$ 5262$ \\
\hline 99th percentile & $\$ 96,497$ & $\$ 4638$ & $\$ 5519$ & $\$ 9884$ & $\$ 31,362$ \\
\hline
\end{tabular}

ART Antiretroviral Therapy, PWID People who inject drugs, MSM Men who have sex with men, HET Heterosexual

a -Includes those in other and unknown HIV risk groups

\$4982 [\$4766, \$5198] for PLHIV in the Northeast HSDA, and all HSDAs were within $6 \%$ of the provincial mean (Fig.1c \& Additional file 1: Table S1).

Adjusted mean hospitalization days ranged from 0.22 $[0.09,0.34]$ in Kootenay Boundary to $0.51[0.02,1.01]$ per person-quarter in East Kootenay, and 10/16 HSDAs were within $20 \%$ of the overall mean (Fig. 3a \& Additional file 1: Table S3). Adjusted mean hospitalization costs ranged from $\$ 176$ [\$62, \$289] in North Vancouver Island, to $\$ 535$ [\$73, \$996] in East Kootenay. Half of all HSDAs were within $20 \%$ of the overall mean, while hospitalization costs in Kootenay Boundary, North Vancouver Island, and Fraser were more than 30\% lower than the provincial mean (Fig. 2a \& Additional file 1: Table S2).

Adjusted mean days with a physician billing record ranged from 3.65 [3.34, 3.95] for PLHIV in the Northern Interior, to $5.87[5.43,6.30]$ per person-quarter for PLHIV in Central Vancouver Island, and 15/16 HSDAs were within $20 \%$ of the adjusted overall mean (Fig. 3b \& Additional file 1: Table S3). Adjusted mean quarterly physician billing costs ranged from $\$ 348$ [\$332, \$363] in Fraser North, to \$455 [\$446, \$465] in Vancouver, and all 16 HSDAs were within $20 \%$ of the adjusted overall mean (Fig. 2b \& Additional file 1: Table S2).

Adjusted prescription drug days ranged from 103 [73, 133] in the Northeast, to $197[128,266]$ per personquarter in East Kootenay, and 14/16 HSDAs were within $20 \%$ of the adjusted overall mean (Fig. 3c \& Additional file 1: Table S3). Adjusted quarterly prescription drug costs ranged from $\$ 170$ [\$83, \$257] in Northeast, to \$366 [\$328, \$403] in Fraser North, and 10/16 of HSDAs were within $20 \%$ of the adjusted overall mean (Fig. 2c \& Additional file 1: Table S2). Furthermore, adjusted prescription drug costs were 43, 38 and 44\% lower than the overall average in the Northwest, Northern Interior and Northeast HSDAs, respectively (Fig. 2c \& Additional file 1: Table S2).

Assigning HSDA by cost rather than frequency of contacts produced minor changes in estimates, with the largest change occurring in the Northwest HSDA, where adjusted quarterly costs were reduced to $\$ 3798$ [\$3181, 
Table 2 Descriptive statistics of selected time-varying covariates by HSDA

\begin{tabular}{|c|c|c|c|c|c|c|c|c|c|}
\hline & \multirow[t]{3}{*}{ Individuals $^{a}$} & \multirow[t]{3}{*}{ Observations } & \multicolumn{7}{|c|}{ Percentage of person-quarters (observations) } \\
\hline & & & \multirow[b]{2}{*}{ Female } & \multicolumn{3}{|c|}{ Risk group $^{b}$} & \multicolumn{3}{|c|}{ ART status } \\
\hline & & & & MSM & PWID & MWID & on ART & off ART & ART-naïve \\
\hline Overall & 9577 & 140,137 & $20.1 \%$ & $33.2 \%$ & $25.6 \%$ & $8.4 \%$ & $74.6 \%$ & $19.4 \%$ & $5.9 \%$ \\
\hline \multicolumn{10}{|l|}{ Interior Health } \\
\hline East Kootenay & 75 & 443 & $33.2 \%$ & $23.0 \%$ & $18.5 \%$ & $0.7 \%$ & $52.8 \%$ & $43.1 \%$ & $4.1 \%$ \\
\hline Kootenay Boundary & 93 & 794 & $35.4 \%$ & $21.9 \%$ & $37.0 \%$ & $2.6 \%$ & $75.3 \%$ & $17.1 \%$ & $7.6 \%$ \\
\hline Okanagan & 546 & 4913 & $23.6 \%$ & $22.0 \%$ & $32.0 \%$ & $8.7 \%$ & $72.8 \%$ & $22.1 \%$ & $5.1 \%$ \\
\hline Thompson Cariboo & 305 & 2668 & $25.6 \%$ & $17.5 \%$ & $34.1 \%$ & $3.8 \%$ & $53.6 \%$ & $40.6 \%$ & $5.8 \%$ \\
\hline \multicolumn{10}{|l|}{ Fraser Health } \\
\hline Fraser East & 573 & 3191 & $35.6 \%$ & $16.1 \%$ & $32.8 \%$ & $6.5 \%$ & $59.9 \%$ & $36.2 \%$ & $3.9 \%$ \\
\hline Fraser North & 3126 & 14,756 & $26.8 \%$ & $14.6 \%$ & $35.7 \%$ & $6.4 \%$ & $61.9 \%$ & $32.3 \%$ & $5.8 \%$ \\
\hline Fraser South & 1569 & 8309 & $34.5 \%$ & $15.5 \%$ & $39.1 \%$ & $4.5 \%$ & $65.4 \%$ & $27.6 \%$ & $7.1 \%$ \\
\hline \multicolumn{10}{|l|}{ Vancouver Coastal Health } \\
\hline Richmond & 270 & 1355 & $28.6 \%$ & $19.2 \%$ & $25.8 \%$ & $4.0 \%$ & $62.1 \%$ & $29.0 \%$ & $8.9 \%$ \\
\hline Vancouver & 7068 & 80,964 & $14.2 \%$ & $44.9 \%$ & $18.1 \%$ & $10.0 \%$ & $81.8 \%$ & $12.7 \%$ & $5.5 \%$ \\
\hline North Shore/Coast Garibaldi & 497 & 2586 & $22.0 \%$ & $23.6 \%$ & $26.5 \%$ & $4.8 \%$ & $62.0 \%$ & $31.4 \%$ & $6.6 \%$ \\
\hline \multicolumn{10}{|l|}{ Island Health } \\
\hline South Vancouver Island & 1509 & 10,869 & $19.1 \%$ & $22.1 \%$ & $33.7 \%$ & $8.1 \%$ & $72.1 \%$ & $20.4 \%$ & $7.5 \%$ \\
\hline Central Vancouver Island & 423 & 3304 & $30.3 \%$ & $19.5 \%$ & $33.5 \%$ & $7.9 \%$ & $68.8 \%$ & $23.9 \%$ & $7.4 \%$ \\
\hline North Vancouver Island & 168 & 1499 & $42.0 \%$ & $8.7 \%$ & $43.2 \%$ & $8.7 \%$ & $65.6 \%$ & $28.2 \%$ & $6.2 \%$ \\
\hline \multicolumn{10}{|l|}{ Northern Health } \\
\hline Northwest & 146 & 1179 & $40.2 \%$ & $3.8 \%$ & $59.0 \%$ & $3.7 \%$ & $53.8 \%$ & $36.8 \%$ & $9.4 \%$ \\
\hline Northern Interior & 335 & 2734 & $38.7 \%$ & $10.8 \%$ & $51.8 \%$ & $2.3 \%$ & $59.2 \%$ & $33.6 \%$ & $7.0 \%$ \\
\hline Northeast & 85 & 573 & $35.1 \%$ & $7.5 \%$ & $23.7 \%$ & $5.4 \%$ & $49.4 \%$ & $44.0 \%$ & $6.6 \%$ \\
\hline
\end{tabular}

ART Antiretroviral Therapy, MSM Men who have sex with men, PWID Person who injects drugs, MWID MSM who inject drugs

a Number of individuals by HSDA is the number of unique individuals ever in a particular HSDA over the course of the study. Given that individuals can appear in multiple HSDAs over time, the sum of individuals by HSDA is higher than the total number of individuals

${ }^{b}$ Remaining percentage includes heterosexual, other and unknown risk

\$4415] from \$3989 [\$3377, \$4601]. Removing PHSA costs from our analysis reduced adjusted quarterly costs to $\$ 3909$ [\$3182, \$4636], from \$4311 [\$3151, \$5471] in the Northeast HSDA, and all other changes were smaller in magnitude (Additional file 1: Table S4).

\section{Discussion}

Our results showed moderate regional variation in medical costs for PLHIV in British Columbia, adjusting for demographic variables and case-mix. For estimates of total costs, including the costs of ART medication, costs per person-quarter in all 16 HSDAs were within $20 \%$ of the overall provincial mean, and cost differences between the highest and lowest cost HSDAs were \$948 [\$571, \$1325] (Fig.1a), equivalent to $21 \%$ of the overall provincial mean. For estimates of total costs, excluding costs of ART medications, 13 of 16 HSDAs in British Columbia were within $20 \%$ of the overall mean, and costs for PLHIV in the highest cost HSDA were $\$ 444$ [\$257, \$630] higher than the lowest cost HSDA per person-quarter, a difference equivalent to $28 \%$ of the overall provincial mean. While ART uptake rates differed, ART costs among PLHIV who were receiving ART were homogeneous across HSDAs.

Variation in annual health care costs in the general population was previously estimated to be $21 \%$ between the highest- and lowest-spending HSDAs in British Columbia, after adjustment for age, sex, aggregated diagnosis group, and health service environment [8]. In the United States, over 31\% of geographic variation in prostate cancer care costs among Medicare recipients was not explained by covariate adjustment, including age, race, year of diagnosis, rural residence, income, other comorbidities, in addition to detailed adjustment for treatment intensity, ancillary procedures, and treatment modalities [5]. Among PLHIV in the United States, mean Medicaid payments were more than double for individuals in New York, compared to Massachusetts [34]. Given that our study cohort comprised a high-cost, 


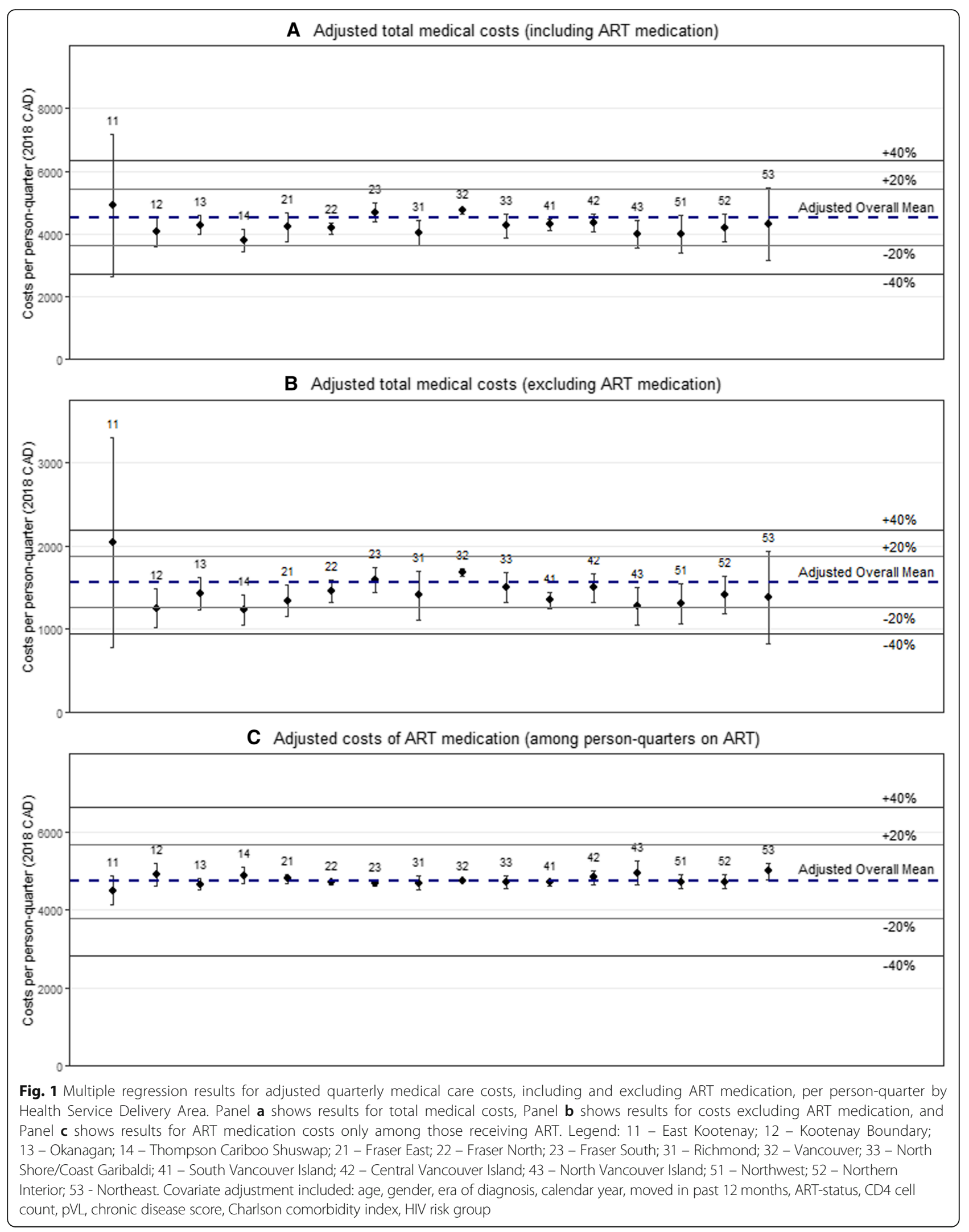




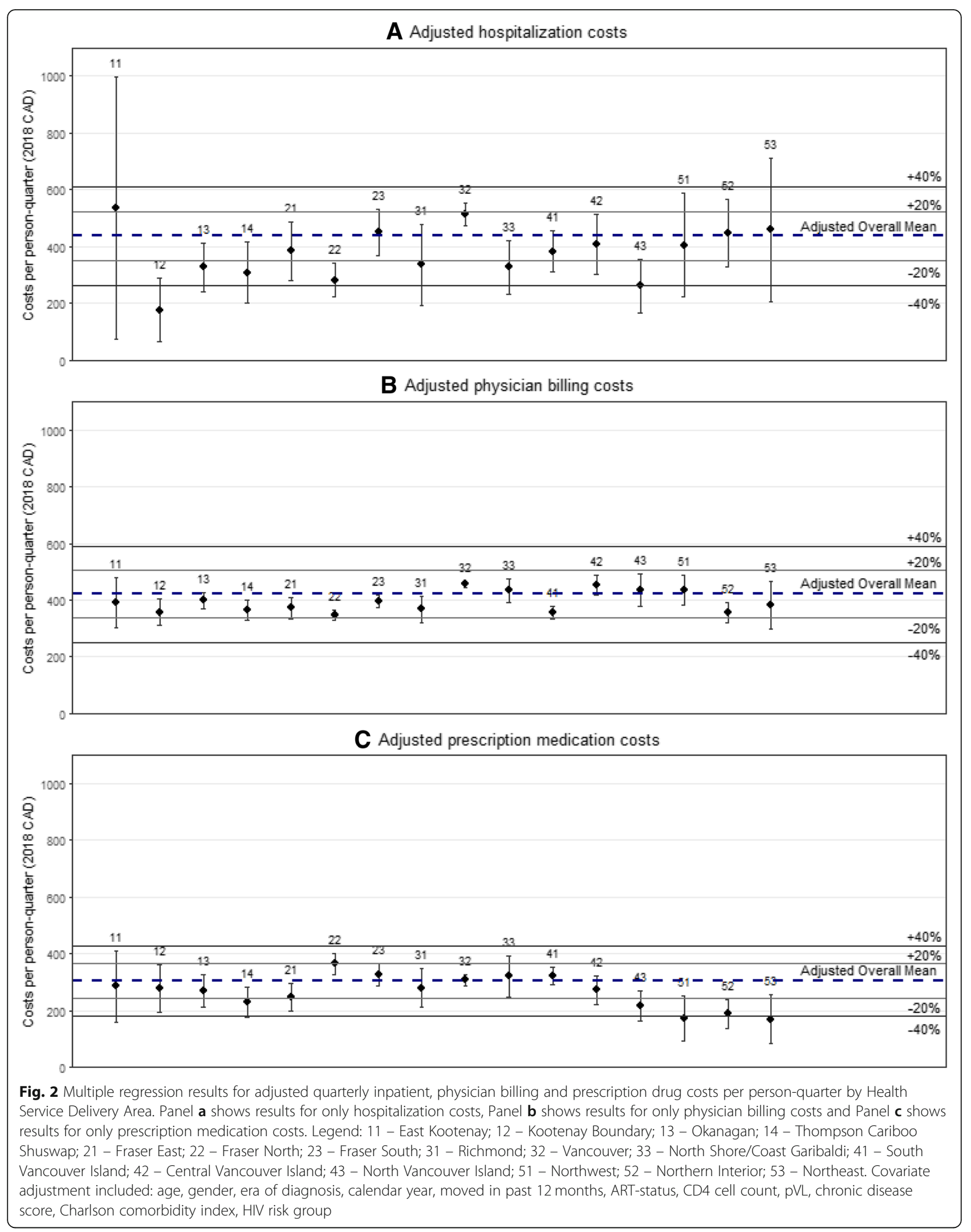




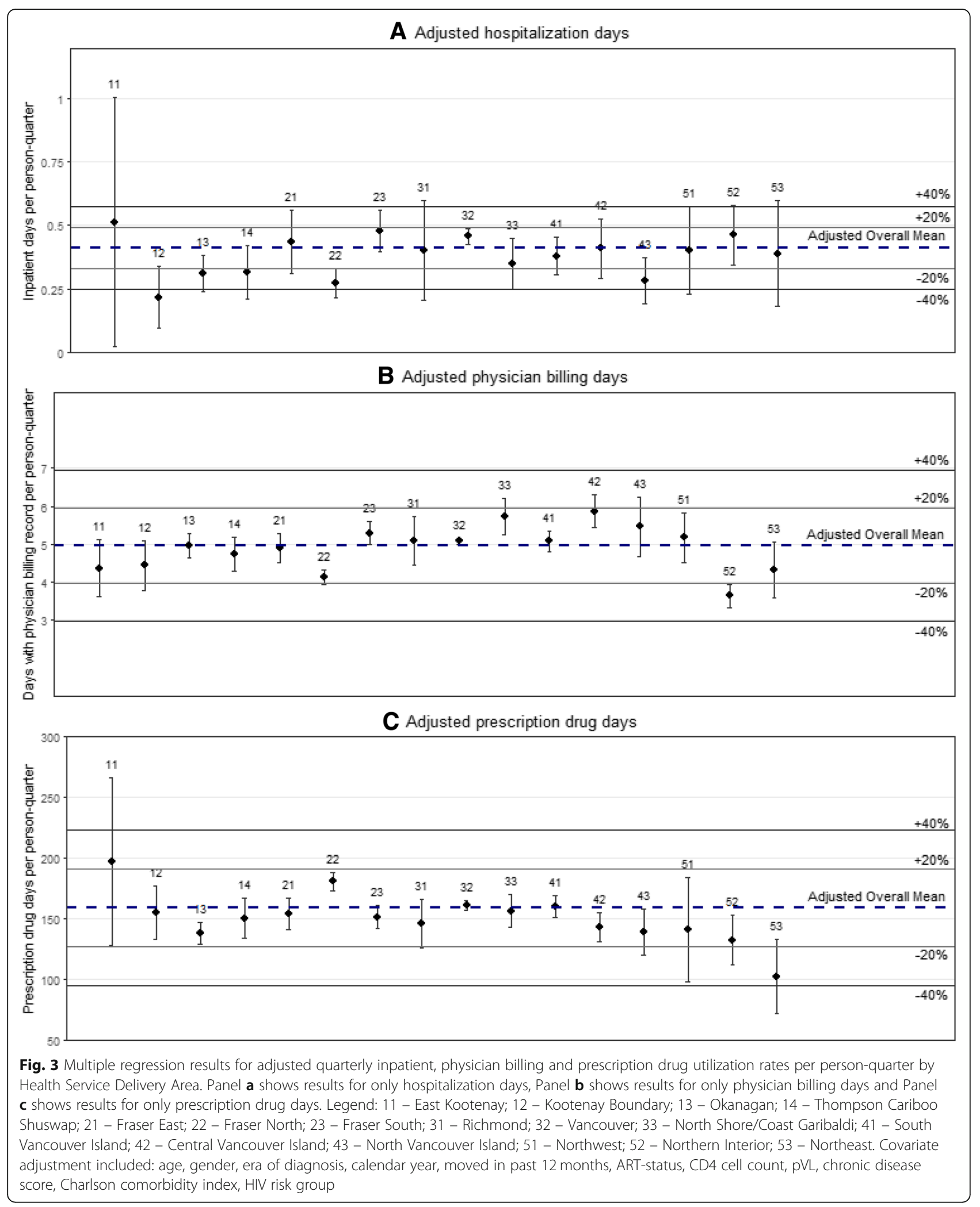

disease-specific subset of the general population, our results suggested that the regional variation observed in medical costs among PLHIV in British Columbia, with and without ART medication costs, was comparable to the general population. As our data did not include individual-level socioeconomic variables such as income, or 
regional measures of health service environments, such as the presence or absence of large hospitals, adjustment for these factors could have further attenuated regional cost differences.

That we observed moderate regional differences in nonART medical costs among PLHIV, after adjusting for demographics, disease progression and other comorbidities, suggests that standards of care were not substantially different across regions for PLHIV. This may be due, in part, to the maturity of the HIV care infrastructure in the province. Previous studies of inter-provincial variation in HIV testing rates have suggested that coordinating all HIV care in the province through a single center may produce better outcomes, by allowing for closer monitoring of PLHIV and better control over standards of care [35], and regional variation tends to be larger when well-defined standards of care and guidelines are absent [2]. Furthermore, the small variation in ART costs among those receiving ART, is likely a result of the evolution of ART treatment, with simpler and safer regimens [36], easing some of the burden on rural health regions by lessening the requirement for highly-specialized clinics and physicians to treat PLHIV effectively [30]. The expansion of the STOP HIV/AIDS program to the entire province in 2012 instituted comprehensive monitoring of PLHIV from testing through care linkage, as well as harmonizing all aspects of HIV care [14, 37], including elimination of pretest counseling, simplified treatment and initiation protocols, and financial incentives for HIV-related care visits [38]. All of these factors, designed to simplify delivery of HIV testing and care, may have contributed to the relatively low levels of adjusted regional variation in health care costs among PLHIV in British Columbia.

In our analysis of the individual components of medical costs and utilization, it was noteworthy that PLHIV in Northern Interior and Northeast HSDAs had 38 and 44\% lower prescription drug costs, 15.3 and $9.1 \%$ lower physician billing costs, and 2.3 and $4.9 \%$ higher hospitalization costs, respectively. PLHIV in both HSDAs were below the overall mean in physician billing days, as well as prescription drug days. Furthermore, PLHIV in these HSDAs had lower levels of ART uptake than the provincial average (Table 2), and if individuals faced barriers in accessing prescription medication or primary care due to geographic remoteness, or other factors, this may have been reflected in higher inpatient utilization $[39,40]$.

There is a substantial literature examining the interaction between the use of inpatient, outpatient, and prescription drug utilization. Previous studies have examined changes to insurance coverage or increased deductibles resulting in lower prescription drug use [41-44], the effect of poor adherence to medication on other health care utilization [45, 46], as well as the effect of increased prescription fills on inpatient costs [47]. In British Columbia, Li et al. (2007) found that increased cost sharing reduced prescription drug utilization and led to increased physician visits among seniors [44]. Furthermore, Law et al. (2017) found that the addition of a small deductible to health plans already requiring co-payment was not associated with reductions in overall prescription drug use or increases in non-pharmaceutical health care utilization [43]. Among PLHIV in the United States, those with higher outpatient utilization had higher inpatient admissions, however, those with no outpatient visits over a 3-month period had significantly higher inpatient admission rates, suggesting that PLHIV with no visits were at higher risk for hospitalization due to a lack of clinical monitoring [48]. While our study was not designed to estimate the causal relationship between changes in outpatient health care utilization and acute care utilization or costs, this could nonetheless be indicative of an association between lower levels of outpatient care and higher levels of inpatient care.

\section{Limitations}

This analysis had several limitations. First, HSDA assignment was subject to some degree of misclassification due to the possibility of individuals receiving care in multiple HSDAs in a given quarter or missing information on HSDA, however, our results were robust to alternative HSDA assignment methods in sensitivity analysis (Additional file 1: Table S4). Second, PHSA costs were assigned to an individual's representative HSDA, and could potentially have affected some regions disproportionately, however, our HSDA-specific cost estimates were robust to the removal of these costs (Additional file 1: Table S4). Furthermore, due to a small number of observations, results from the East Kootenay HSDA should be interpreted with caution. Finally, as with all non-experimental studies, we cannot rule out the possibility that our coefficient estimates may have been subject to some degree of bias from unmeasured confounding factors [49]. It is likely that some degree of the variation in regional costs could be attributable to incomplete case-mix adjustment. While our study included detailed information on HIV treatment and disease progression, it is possible that the prevalence and severity of comorbid conditions were not fully accounted for. Finally, our goal was to estimate variation among HSDAs in costs and utilization rates, and we did not examine the association between health care costs and quality of care, clinical outcomes or long-term spending by region. Further investigation is needed into the association between utilization rates of different health care components, particularly in rural and remote regions, to determine if lack of access, socioeconomic factors or other 
barriers to care are leading to higher hospitalization utilization and costs, or other adverse outcomes.

\section{Conclusions}

We estimated the magnitude of geographic variation in medical costs and utilization rates among PLHIV in British Columbia from 2010 to 2014, using linked, individual-level data to characterize regional differences. Despite substantial regional differences in demographic composition, ART uptake, and HIV care engagement, we found that variation in medical costs among PLHIV, both including and excluding ART medication, was comparable to the overall population of British Columbia, adjusting for demographic variables and case-mix. While there was generally modest variation among HSDAs for hospitalizations, physician billings and non-ART prescriptions, our results indicated possible substitution between outpatient care and inpatient care among PLHIV in the most rural regions of the province.

\section{Additional files}

Additional file 1: This supplement contains the data plotted in Figs. 1, 2 and 3 of the manuscript, as well as results from sensitivity analysis. It also includes a map of Health Service Delivery Areas in British Columbia. (DOCX $532 \mathrm{~kb}$ )

\section{Abbreviations}

AIDS: Acquired immunodeficiency syndrome; ART: Antiretroviral therapy; AUC: Area under the curve; BC: British Columbia; CAD: Canadian dollars; CCl: Charlson comorbidity index; CDS: Chronic disease score; GLM: Generalized linear model; HA: Health authority; HET: Heterosexual; HIV: Human immunodeficiency virus; HSDA: Health service delivery area; IAS-USA: International Antiviral Society-USA; MSM: Men who have sex with men; MSP: Medical services plan; MWID: Men who have sex with men and inject drugs; PLHIV: People living with HIV; pVL: Plasma viral load; PWID: People who inject drugs

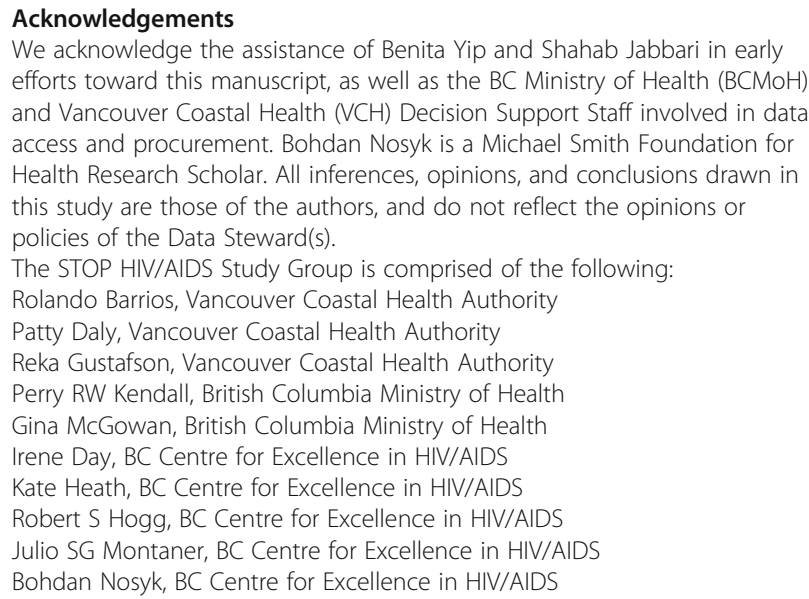
efforts toward this manuscript, as well as the $\mathrm{BC}$ Ministry of Health $(\mathrm{BCMOH})$ and Vancouver Coastal Health (VCH) Decision Support Staff involved in data access and procurement. Bohdan Nosyk is a Michael Smith Foundation for Health Research Scholar. All inferences, opinions, and conclusions drawn in this study are those of the authors, and do not reflect the opinions or policies of the Data Steward(s).

The STOP HIV/AIDS Study Group is comprised of the following:

Rolando Barrios, Vancouver Coastal Health Authority

Patty Daly, Vancouver Coastal Health Authority

Reka Gustafson, Vancouver Coastal Health Authority

Perry RW Kendall, British Columbia Ministry of Health Gina McGowan, British Columbia Ministry of Health Irene Day, BC Centre for Excellence in HIV/AIDS Kate Heath, BC Centre for Excellence in HIV/AIDS Robert S Hogg, BC Centre for Excellence in HIV/AIDS Julio SG Montaner, BC Centre for Excellence in HIV/AIDS Bohdan Nosyk, BC Centre for Excellence in HIV/AIDS

\section{Authors' contributions}

$\mathrm{BN}$ designed the study. BE managed the literature searches, summaries of previous related work, undertook the statistical analysis, and wrote the first draft of the manuscript. JEM, DP, and BN provided critical input into the design, analysis and interpretation of results. JSGM contributed to study design, conceptualized the cohort on which this analysis was based, and secured access to the data. All authors have approved the final manuscript.

\section{Funding}

This study was funded by the British Columbia Ministry of Health-funded Seek and Treat for Optimal Prevention of HIV \& AIDS program and Canadian Institutes of Health Research (201610PJT). The funding bodies had no direct role the design of the study, collection, analysis, and interpretation of data, or in writing the manuscript.

\section{Availability of data and materials}

The data that support the findings of this study are available from Seek And Treat For Optimal Prevention Of HIV/AIDS ${ }^{\circledR}$ (STOP HIV/AIDS ${ }^{\circledR}$ ) but restrictions apply to the availability of these data, which were used under license for the current study, and so are not publicly available. Data are however available from the authors upon reasonable request and with permission of Seek And Treat For Optimal Prevention Of HIV/AIDS ${ }^{\oplus}$ (STOP HIV/AIDS $\left.{ }^{\circledR}\right)$.

\section{Ethics approval and consent to participate}

This study received approval from the University of British Columbia/ Providence Health Care Research Ethics Board (H17-01929).

\section{Consent for publication}

Not applicable.

\section{Competing interests}

The authors declare that they have no competing interests.

\section{Author details}

${ }^{1}$ BC Centre for Excellence in HIV/AIDS, St. Paul's Hospital, 613-1081 Burrard St, Vancouver, BC V6Z 1Y6, Canada. 'Faculty of Medicine, Department of Epidemiology, Biostatistics and Occupational Health, McGill University, 1020 Pine Avenue West, Montreal, QC H3A 1A2, Canada. ${ }^{3}$ Division of AIDS, Department of Medicine, University of British Columbia, 667-1081 Burrard Street, Vancouver, BC V6Z 1Y6, Canada. ${ }^{4}$ Faculty of Health Sciences, Simon Fraser University, Blusson Hall, Room 11300, 8888 University Drive, Burnaby, BC V5A 156, Canada.

Received: 13 February 2019 Accepted: 1 August 2019

Published online: 03 September 2019

\section{References}

1. Epstein AM. Geographic variation in Medicare spending. N Engl J Med. 2010;363(1):85-6. https://doi.org/10.1056/NEJMe1005212 Epub 2010 May 12.

2. Mahar AL, Coburn NG, Kagedan DJ, Viola R, Johnson AP. Regional variation in the management of metastatic gastric cancer in Ontario. Curr Oncol. 2016:23(4):250-7.

3. Panczak R, Luta X, Maessen M, Stuck AE, Berlin C, Schmidlin K, Reich O, von Wyl V, Goodman DC, Egger M, et al. Regional variation of cost of Care in the Last 12 months of life in Switzerland: small-area analysis using insurance claims data. Med Care. 2017;55(2):155-63.

4. Treskova M, Kuhlmann A, Bogner J, Hower M, Heiken H, Stellbrink HJ, Mahlich J, Schulenburg JM, Stoll M. Analysis of contemporary HIV/AIDS health care costs in Germany: driving factors and distribution across antiretroviral therapy lines. Medicine. 2016;95(26):0000000000003961.

5. Wang S-Y, Wang R, Yu JB, Ma X, Xu X, Kim SP, Soulos PR, Saraf A, Gross CP. Understanding regional variation in Medicare expenditures for initial episodes of prostate Cancer care. Med Care. 2014:52(8):680-7.

6. Hadley J, Reschovsky JD, O'Malley JA, Landon BE. Factors associated with geographic variation in cost per episode of care for three medical conditions. Heal Econ Rev. 2014;4:8-8.

7. Newhouse JP, Garber AM. Geographic variation in health care spending in the United States: insights from an institute of medicine report. Jama. 2013; 310(12):1227-8.

8. Lavergne MR, Barer M, Law MR, Wong ST, Peterson S, McGrail K. Examining regional variation in health care spending in British Columbia, Canada. Health Policy. 2016;120(7):739-48.

9. Ohinmaa A, Zheng Y, Jeerakathil T, Klarenbach S, Häkkinen U, Nguyen T, Friesen D, Ruseski J, Kaul P, Ariste $R$, et al. Trends and regional variation in hospital mortality, length of stay and cost in Hospital of Ischemic Stroke 
Patients in Alberta accompanying the provincial reorganization of stroke care. J Stroke Cerebrovasc Dis. 2016;25(12):2844-50.

10. HIV Monitoring Quarterly Report for British Columbia. http://stophivaids.ca/ gmr/2017-Q2/\#/bc. Accessed 30 Aug 2017.

11. BC Ministry of Health: From Hope to Health: Towards an AIDS-Free Generation (Progress Report 2015/16). 2016.

12. $B C$ Ministry of Health: Rural health services in BC: a policy framework to provide a system of quality care. 2015.

13. Characteristics of ARV-Prescribing Physicians in BC. http://www.cfenet.ubc. ca/sites/default/files/uploads/HIV-pulse/hiv-pulse-volume-1.pdf. Accessed 25 July 2018.

14. Lourenco L, Lima VD, Heath K, Nosyk B, Gilbert M, Colley G, Consolacion T, Barrios R, Hogg R, Krajden M, et al. Process monitoring of an HIV treatment as prevention program in British Columbia, Canada. J Acquir Immune Defic Syndr. 2014;67(3):e94-e109.

15. MacKenzie LJ, Hull MW, Samji H, Lima VD, Yip B, Zhang W, Lourenço L, Colley G, Hogg RS, Montaner JSG. Is there a rural/urban gap in the quality of HIV care for treatment-naïve HIV-positive individuals initiating antiretroviral therapy in British Columbia? AIDS Care. 2017;29(10):1218-26.

16. Heath K, Samji H, Nosyk B, Colley G, Gilbert M, Hogg RS, Montaner JSG. Cohort profile: seek and treat for the optimal prevention of HIV/AIDS in British Columbia (STOP HIV/AIDS BC). Int J Epidemiol. 2014;43(4):1073-81.

17. Nosyk B, Colley G, Yip B, Chan K, Heath K, Lima VD, Gilbert M, Hogg RS, Harrigan PR, Montaner JS. Application and validation of case-finding algorithms for identifying individuals with human immunodeficiency virus from administrative data in British Columbia, Canada. PLoS One. 2013;8(1):28.

18. Rural Practice Programs. https://www2.gov.bc.ca/gov/content/health/ practitioner-professional-resources/physician-compensation/rural-practiceprograms. Accessed 1 Nov 2017.

19. Lavergne MR. Identifying distinct geographic health service environments in British Columbia, Canada: cluster analysis of population-based administrative data. Healthc Policy. 2016;12(1):43-51.

20. British Columbia Centre for Excellence in HIV/AIDS: Drug treatment and laboratory database. 2014.

21. British Columbia Centre for Disease Control: Provincial HIV/AIDS Surveillance Database. 2014

22. British Columbia Ministry of Health: Medical services plan database. 2014.

23. British Columbia Ministry of Health: Discharge Abstract Database. 2014.

24. British Columbia Ministry of Health: PharmaNet Database. 2014.

25. Statistics Canada: Vital Statistics. 2014.

26. Thompson MA, Aberg JA, Hoy JF, Telenti A, Benson C, Cahn P, Eron JJ, Gunthard HF, Hammer SM, Reiss P, et al. Antiretroviral treatment of adult HIV infection: 2012 recommendations of the international antiviral societyUSA panel. Jama. 2012;308(4):387-402.

27. Nosyk B, Lima V, Colley G, Yip B, Hogg RS, Montaner JS. Costs of health resource utilization among HIV-positive individuals in British Columbia, Canada: results from a population-level study. Pharmacoeconomics. 2015; 33(3):243-53.

28. Nosyk B, Yip B, Lima VD, Hogg RS, Montaner JSG. STOP HIV/AIDS study group: antiretroviral drug costs and prescription patterns in British Columbia, Canada: 1996-2011. Med Care. 2014;52(4):362-9.

29. Lima VD, Druyts E, Montaner JS, Hogg RS. Regional and temporal trends in migration among people living with HIV/AIDS in British Columbia, 19932005. Can J Public Health. 2010:101(1):44-9.

30. Lima VD, Goldberg N, Lourenco L, Chau W, Hogg RS, Guillemi S, Barrios R, Montaner JS. Virologic suppression and mortality of patients who migrate for HIV care in the province of British Columbia, Canada, from 2003 to 2012: a retrospective cohort study. BMC Health Serv Res. 2015;15(376):015-1042.

31. Clark DO, Von Korff M, Saunders K, Baluch WM, Simon GE. A chronic disease score with empirically derived weights. Med Care. 1995;33(8):783-95.

32. Charlson ME, Pompei P, Ales KL, Mackenzie CR. A new method of classifying prognostic comorbidity in longitudinal studies: development and validation. J Chronic Dis. 1987:40(5):373-83.

33. Manning WG, Basu A, Mullahy J. Generalized modeling approaches to risk adjustment of skewed outcomes data. J Health Econ. 2005;24(3):465-88.

34. Fleishman JAMA, Voss CC, Moore RD, Gebo KA. Expenditures for persons living with HIV enrolled in Medicaid, 2006-2010. J Acquir Immune Defic Syndr. 2016;72(4):408-15.

35. Raboud JM, Loutfy MR, Su D, Bayoumi AM, Klein MB, Cooper C, Machouf N, Rourke S, Walmsley S, Rachlis A, et al. Regional differences in rates of HIV-1 viral load monitoring in Canada: insights and implications for antiretroviral care in high income countries. BMC Infect Dis. 2010;10(1):40.

36. Gunthard HF, Saag MS, Benson CA, del Rio C, Eron JJ, Gallant JE, Hoy JF, Mugavero MJ, Sax PE, Thompson MA, et al. Antiretroviral drugs for treatment and prevention of HIV infection in adults: 2016 recommendations of the international antiviral society-USA panel. Jama. 2016;316(2):191-210.

37. Olding M, Enns B, Panagiotoglou D, Shoveller J, Harrigan PR, Barrios R, Kerr T, Montaner JSG, Nosyk B. A historical review of HIV prevention and care initiatives in British Columbia, Canada: 1996-2015. J Int AIDS Soc. 2017;20(1):21941

38. Nosyk B, Krebs E, Min JE, Ahamad K, Buxton J, Goldsmith C, Hull M, Joe R, Krajden M, Lima VD, et al. The 'Expanded HIV care in opioid substitution treatment' (EHOST) cluster-randomized, stepped-wedge trial: a study protocol. Contemp Clin Trials. 2015;45(Pt B:201-9.

39. Ricketts TC, Randolph R, Howard HA, Pathman D, Carey T. Hospitalization rates as indicators of access to primary care. Health Place. 2001;7(1):27-38.

40. Bindman AB, Grumbach K, Osmond D, Komaromy M, Vranizan K, Lurie N, Billings J, Stewart A. Preventable hospitalizations and access to health care. Jama. 1995;274(4):305-11.

41. Goldman DP, Joyce GF, Zheng Y. Prescription drug cost sharing: associations with medication and medical utilization and spending and health. Jama. 2007:298(1):61-9.

42. Kesselheim AS, Huybrechts KF, Choudhry NK, Fulchino LA, Isaman DL, Kowal MK, Brennan TA. Prescription drug insurance coverage and patient health outcomes: a systematic review. Am J Public Health. 2015;105(2):e17-30. https://doi.org/10.2105/AJPH.2014.302240.

43. Law MR, Cheng L, Worthington H, Mamdani M, McGrail KM, Chan FKI, Majumdar SR. Impact of income-based deductibles on drug use and health care utilization among older adults. CMAJ. 2017;189(19):E690-6.

44. Li X, Guh D, Lacaille D, Esdaile J, Anis AH. The impact of cost sharing of prescription drug expenditures on health care utilization by the elderly: own- and cross-price elasticities. Health Policy. 2007;82(3):340-7.

45. Ho PM, Bryson CL, Rumsfeld JS. Medication adherence. Circulation. 2009; 119(23):3028-35.

46. Sokol MC, McGuigan KA, Verbrugge RR, Epstein RS. Impact of medication adherence on hospitalization risk and healthcare cost. Med Care. 2005:43(6):521-30.

47. Stuart BC, Doshi JA, Terza JV. Assessing the impact of drug use on hospital costs. Health Serv Res. 2009:44(1):128-44.

48. Fleishman JA, Moore RD, Conviser R, Lawrence PB, Korthuis PT, Gebo KA. Associations between outpatient and inpatient service use among persons with HIV infection: a positive or negative relationship? Health Serv Res. 2008; 43(1 Pt 1):76-95.

49. Grimes DA, Schulz KF. Bias and causal associations in observational research. Lancet. 2002;359(9302):248-52.

\section{Publisher's Note}

Springer Nature remains neutral with regard to jurisdictional claims in published maps and institutional affiliations.

Ready to submit your research? Choose BMC and benefit from:

- fast, convenient online submission

- thorough peer review by experienced researchers in your field

- rapid publication on acceptance

- support for research data, including large and complex data types

- gold Open Access which fosters wider collaboration and increased citations

- maximum visibility for your research: over $100 \mathrm{M}$ website views per year

At BMC, research is always in progress.

Learn more biomedcentral.com/submissions 